\title{
Dyadic perceptions of the decision process in families living with lung cancer
}

\author{
Lyndsey M. Miller, RN, BSN, BA, \\ PhD candidate at Oregon Health and Science University, School of Nursing. 3455 SW US \\ Veterans Hospital Rd., SN-ORD, Portland, OR 97239 \\ Donald R. Sullivan, MD, MA, and \\ Assistant Professor in the Department of Medicine, Division of Pulmonary \& Critical Care \\ Medicine, Oregon Health and Science University
}

Karen S. Lyons, PhD

Associate Professor in the School of Nursing and the Department of Psychiatry, Oregon Health and Science University

\section{Abstract}

Objective-The purpose of this study was to use dyadic analyses to identify determinants of patients' and family members' perceptions of how families living with lung cancer make decisions (negative and positive aspects).

Design-Cross-sectional.

Setting-Community setting.

Sample-109 family care dyads (patient and family member) recruited from a statewide cancer registry.

Methods-Surveys were completed in-person, separately and privately for each member of the family care dyad. Secondary analysis was completed using multilevel modeling.

Main Research Variables-Negative and positive aspects of the decision process.

Findings-Level 1 data revealed that there was significant variability, across care dyads, in how positive and negative the decision process was perceived. Level 2 results for negative perceptions of decision making indicated that both patient and family member perceptions were significantly associated with one's own depressive symptoms and feelings of not being listened to by others. Level 2 results for positive perceptions of decision making indicated that both patient and family member perceptions were significantly inversely associated with one's own feelings of not being listened to and being in a non-spousal relationship together. Additionally, for family members, perceptions were more positive when the patient was older. Together, the models accounted for $29 \%$ and $33 \%$ of patients' and family members' perceptions of the negative aspects of the decision

Corresponding author: (971) 239-8191. millerly@ohsu.edu.

Disclosures: The authors have no conflicts of interest to disclose. 
process, respectively, and 39\% and 38\% of patients' and family members' perceptions of the positive aspects of the decision process, respectively.

Conclusions-This study highlights the complexity of the decision process in families with lung cancer, and underscores the importance of the care dyad feeling listened to by family members in the context of a life-threatening illness.

Implications for Nursing-Nurses assisting families with lung cancer decisions should be aware of the importance of the dynamics of the care dyad in how the decision process is perceived by both patients and their family members.

Knowledge Translation-In the context of lung cancer, it is important for both patients and family members to be heard in order to minimize negative perceptions and maximize positive perceptions of the decision process. Dyads exhibiting depressive symptoms are at significantly higher risk of negative perceptions of the decision process. Spousal dyads and family members of older patients perceived the decision process more positively, and thus could be in a more protective relationship than non-spouse dyads during the decision process.

\section{Keywords}

decision making; multilevel modeling; families; communication; lung cancer

A diagnosis of cancer impacts both patients and family members, and leads to many decisions that families often work through and process together. However, the life-changing nature of a cancer diagnosis does not necessarily bring about greater communication or agreement in families (Siminoff, Dorflinger, Agyemang, Baker, \& Wilson-Genderson, 2012; Siminoff, Rose, Zhang, \& Zyzanski, 2006; Venetis, Greene, Checton, \& Magsamen-Conrad, 2015; Zhang, Zyzanski, \& Siminoff, 2010). Indeed, family communication often breaks down in the context of cancer (Badr \& Carmack Taylor, 2006; Zhang \& Siminoff, 2003). This may be especially true in lung cancer-the leading cause of cancer related mortality in the United States-(Howlader et al., 2013) due to the potential for blame associated with smoking and family conflict surrounding smoking cessation (Badr \& Carmack Taylor, 2006; Lobchuk, Murdoch, McClement, \& McPherson, 2008; Siminoff, Wilson-Genderson, \& Baker, 2010; Stone, Mikucki-Enyart, Middleton, Caughlin, \& Brown, 2012; Zhang, 2003). Despite these challenges, the majority of patients with cancer and their family members want to participate in the decision-making process together (Davison, Goldenberg, Gleave, \& Degner, 2003; Shin et al., 2013; Shin et al., 2011). Researchers of families with lung cancer have called for intervention approaches to promote better family decision making (Kramer, Kavanaugh, Trentham-Dietz, Walsh, \& Yonker, 2010). However, the development of interventions is impeded by a lack of understanding regarding the complexity of the decision process and perceptions of this process within the care dyad. The goal of this study is to understand the care dyad's perception of the decision process in families living with lung cancer.

Lung cancer is an aggressive disease involving what many patients perceive as an onslaught of difficult treatment and care-planning decisions. The rapid disease course intensifies patients' and family members' perceptions of the negative aspects (e.g. conflict, disagreement, avoidance) of how families communicate and make decisions (Siminoff, 
Zyzanski, Rose, \& Zhang, 2008; Zhang, 2003; Zhang et al., 2010). In contrast, positive perceptions of communication about cancer in families (e.g. family cooperation, respectful communication) may be beneficial for care dyads and lead to greater agreement about decision-making (Manne et al., 2004; Shin et al., 2013; Siminoff et al., 2012). A variety of factors such as declining mental and physical health, and the quality of the family care dyad's relationship have been influential in studies of how communication and decisionmaking are perceived by cancer and non-cancer dyads (Hagedoorn, Kuijer, Wobbes, \& Sanderman, 2000; Menne, Tucke, Whitlatch, \& Feinberg, 2008). Depressive symptoms are high in lung cancer dyads in general (Siminoff et al., 2010; Sullivan et al., 2014), and are also related to negative perceptions of the decision process (Siminoff et al., 2008; Stone et al., 2012; Zhang, 2003; Zhang et al., 2010). Finally, the family's responsiveness or listening may be important to dyads' perceptions of the decision-making process (Manne et al., 2004; Rose, Radziewicz, Bowman, \& O’Toole, 2008).

Previous studies have demonstrated significant discordance between lung cancer patients' and family members' perceptions of the decision-process, which makes it essential to analyze the perceptions of both members of the care dyad (Shin et al., 2013; Siminoff et al., 2012; Siminoff et al., 2006; Zhang et al., 2010). Moreover, research that has involved families living with a variety of cancer types points to an interdependent emotional system at work in the family care dyad (Badr \& Carmack Taylor, 2006; Hagedoorn, Sanderman, Bolks, Tuinstra, \& Coyne, 2008; Stone et al., 2012). Thus, each dyad member's perception of the decision-process is important to the dyad, and could be determined by factors in dyad members' own lives or in each other's lives (i.e. cross-partner effects) (Berg \& Upchurch, 2007; Stone et al., 2012). An analytic method that takes into account the interrelatedness of the patients and family members is crucial in understanding dyads' perceptions of the family decision process in lung cancer and the determinants of each member's perceptions. Other studies of lung cancer dyads have examined aspects of communication and the decision process from one person's perspective (e.g. Stone et al., 2012), or used methods that do not take into account the interrelatedness of the dyadic data, such as group-level correlation analyses (e.g. Siminoff et al., 2008). This is the first known dyadic study to use multilevel modeling (an appropriate approach for preserving dyadic data) to examine patients' and family members' perceptions of the decision process in families living with lung cancer.

The purpose of this study is to use dyadic analyses to identify determinants of patients' and family members' perceptions, both negative and positive, regarding how families living with lung cancer make decisions.

\section{Methods}

\section{Participants}

This study is a secondary analysis of baseline data from a longitudinal study on families living with lung cancer. The original study has been described in detail elsewhere (Lyons et al., 2014). Briefly, a statewide cancer registry was used to recruit participants. Eligibility criteria for patients included a diagnosis within the past 6 months of a primary invasive nonsmall cell lung cancer, and the ability to nominate a family member who was willing and eligible to participate in the study and also involved in the patient's care. Family members 
and patients were required to have access to a telephone, speak English, live within 50 miles of the metro area of Portland, Oregon, and be at least 18 years of age. Staff from the cancer registry made initial contact with patients by letter with a description of the study. Interested participants mailed back a reply form to the study project director, who then determined eligibility over the telephone using contact information provided by the potential participant. Patients and family members provided informed consent separately, in-person with project director, followed by the completion of baseline interviews (approximately 45-60 minutes). This study was approved by the institutional review board at Oregon Health \& Science University.

\section{Measures}

Family decision process: Negative aspects-Patients' and family members' perceptions of the negative aspects ( 11 items) of the decision process of families living with lung cancer were measured using the subscale of the Decision Process measure (Noelker, Townsend, \& Deimling, 1984). In this measure, items are either not endorsed (score of 0) or endorsed (score of 1 ) for a scale range of 0 to 11 on the negative aspects subscale. An example item for the negative aspects subscale is: "When decisions concerning your family member are discussed does anyone become overly tense or upset?" In this study, the negative aspects subscale of the decision process scale demonstrated good internal consistency (patients' $a=.87$; family members' $a=.84$ ).

Family decision process: Positive aspects-Patients' and family members' perceptions of the positive aspects (5 items) of the decision process of families living with lung cancer were measured using the subscale of the Decision Process measure (Noelker et al., 1984). In this measure, items are either not endorsed (0) or endorsed (1) for a scale range of 0 to 5 on the positive aspects subscale. An example item for the positive aspects subscale is: "When decisions concerning your family member are discussed does everyone cooperate to make a decision?" In this study, the positive aspects subscale demonstrated good internal consistency (patients' $a=.79$; family members' $a=.82$ ).

Relationship quality-Patients' ratings of relationship quality in the dyad was measured using the Mutuality scale (Archbold, Stewart, Greenlick, \& Harvath, 1990). Although data were collected from both patients and family members for this study, we included only one perception to conserve the ratio of variables to sample size, and we chose the patients' perceptions according to previous literature indicating that it may be the more salient perspective (Lyons et al., 2015). Patients responded to 15 items about their relationship with each other, using a Likert scale from 0 (not at all) to 4 (a great deal). High scores indicate higher levels of relationship quality. The scale demonstrated strong internal consistency in this study (patient: $a=.89$ ).

Physical health-Physical health of family members was measured by the Physical Component Summary (PCS) of the Short-form 36 (SF-36, v.2) (Ware, 2005). The PCS includes scales of physical functioning, role-physical, pain, and general health. Scores were transformed to U.S. norm-based scoring (i.e. mean of 50 and standard deviation of 10) 
(Ware, 2005). Scores can range from 0-100, with higher scores indicating better physical health status. Internal consistency of the PCS in this sample was excellent $(\alpha=.89)$.

Depressive symptoms-The Center for Epidemiological Studies-Depression (CES-D) scale (Radloff, 1977) was used to measure depressive symptoms in both patients and family members. Each of the 20 items are rated on a Likert-type scale ranging from 0 (rarely/none of the time) to 3 (most/all of the time). Scores are summed for a possible range of 0 to 60 , and higher scores signal greater depressive symptoms. In the current study, reliability of the CES-D was good (patients' $a=.83$; family members' $a=.86$ ).

Feelings of not being listened to by others-The degree to which patients and family members did not feel that they were listened to by other family members was measured using a single item measure: "How much difficulty do you have getting your family to listen to your opinion?"(Noelker et al., 1984) The item is rated on a 3-point scale ranging from 0 (none) to 2 (a great deal).

Statistical Analyses-Analysis of the family dyad data was conducted using multilevel modeling and the software program Hierarchical Linear Modeling (HLM), version 7(Raudenbush, Bryk, \& Congdon, 2011). Multilevel modeling (MLM) accounts for nonindependence of dyadic data by estimating and controlling for the degree of shared variance (Barnett, Marshall, Raudenbush, \& Brennan, 1993; Sayer \& Klute, 2005). In MLM, Level 1 analyzes the unconditional (i.e., no covariates included) model of the decision process. Level 1 generates estimates of the average values for the two equivalent decision process measures (one for the patient one for the family member) of each outcome variable (negative aspects and positive aspects). Additionally, Level 1 estimates the amount of variability around the averages. At Level 2, covariates are included to explain this variability. In this study, separate models were run for perceptions of the negative and positive aspects of the family decision process.

Specifically, the Level 1 (within-dyads) model represents the decision process scores $(Y$ ) for each of patient and family members as the sum of a latent true score ( $\beta_{1}$ for the patient and $\beta_{2}$ for the family member) plus a residual term $r$ that captures measurement error and was specified as:

$$
\mathrm{Y}_{i j}=\beta_{1 j}\left(\text { PATIENT }_{i j}\right)+\beta_{2 j}\left(\text { FAMILY }_{i j}\right)+\mathrm{r}_{i j}
$$

where $\mathrm{Y}_{i j}$ represents the decision process score $i$ in dyad $j$. PATIENT is an indicator variable taking on a value of 1 if the response was obtained from a patient and 0 if the response was obtained from a family member. FAMILY is an indicator variable taking on a value of 1 if the response was obtained from a family member and 0 if the response was obtained from a patient. Thus, each of the two decision process models (positive and negative aspects) results in two scores $-\beta_{1 j}$ and $\beta_{2 j}$-that represent the patient's and family member's latent decision process scores, respectively.

The Level 2 (between-dyads) models include predictors to explain the variability across dyads. Based on hypothesized explanatory variables and preliminary correlational analysis, 
independent variables were included in Level 2 models where the parameters for latent true decision process scores of patients $\left(\beta_{1 j}\right)$ and family members $\left(\beta_{2 j}\right)$ become the outcome variables and are specified as:

$$
\begin{aligned}
& \beta_{1 j}=\gamma_{10}+\left[\gamma_{11} \text { Predictor }_{1}+\gamma_{1 \mathrm{n}} \text { Predictor }_{\mathrm{n}}\right]+u_{1 \mathrm{j}} \\
& \beta_{2 j}=\gamma_{20}+\left[\gamma_{21} \text { Predictor }_{1}+\gamma_{2 \mathrm{n}} \text { Predictor }_{\mathrm{n}}\right]+u_{2 \mathrm{j}}
\end{aligned}
$$

$\gamma_{10}$ and $\gamma_{20}$ are the Level 2 intercepts, representing average values of the decision process for patient and family member, respectively, adjusted for the effects of the predictors in each equation. Thus, we examined two models at Level 2 (negative and positive aspects), each with two outcomes: 1a) the patients' perceptions of the negative aspects of the decision process, $1 \mathrm{~b}$ ) the family members' perceptions of the negative aspects of the decision process, 2a) the patients' perceptions of the positive aspects of the decision process, and $2 \mathrm{~b}$ ) the family members' perceptions of the positive aspects of the decision process.

\section{Results}

\section{Sample Demographics}

This study included data from the 109 patient-family caregiver dyads who had complete information on baseline measures ( $96 \%$ of the original study sample). Sample demographic and descriptive statistics are reported in Table 1. Patients were mostly male (54\%), and nonHispanic white (93\%) older adults (mean age $69 \pm 12$ years). Family member participants were mostly female (74\%) spouses or partners (70\%) with an average age of $61 \pm 14$ years.

\section{Negative Perceptions of the Family's Decision Process}

Level 1 results for the negative aspects of the decision process revealed that patients' perceptions were similar, on average, to family members' perceptions $\left(\chi^{2}=1.11, \mathrm{p}=.29\right)$. Additionally, there was significant variability in how negative the decision process was perceived by both patients $\left(\chi^{2}=724.57, \mathrm{p}<.001\right)$ and family members $\left(\chi^{2}=694.45, \mathrm{p}<\right.$. 001). Level 2 results for negative perceptions of the decision process indicated that both patient and family member perceptions were significantly associated with one's own depressive symptoms and feelings of not being listened to by others. All models controlled for relationship quality, physical health of the family member, and stage of lung cancer (see Table 2). Together these independent variables accounted for $29 \%$ of the variance in the patients' perceptions and $33 \%$ of the family members' perceptions of the negative aspects of the decision process.

\section{Positive Perceptions of the Family's Decision Process}

Level 1 results for the positive aspects of the decision process revealed that patients' perceptions were similar, on average, to family members' perceptions $\left(\chi^{2}=.10, \mathrm{p}=.50\right)$. Additionally, there was significant variability in how positive the decision process was perceived by both the patients $\left(\chi^{2}=511.89, \mathrm{p}<.001\right)$ and the family members $\left(\chi^{2}=\right.$ $602.53, \mathrm{p}<.001)$. Level 2 results for the positive aspects of the decision process indicated that both patient and family member perceptions were significantly inversely associated with one's own feelings of not being listened to and with being in a non-spousal relationship 
together. Additionally, for family members, perceptions were more positive when the patient was older. All models controlled for relationship quality, physical health of the family member, and stage of lung cancer (see Table 3). Together these independent variables accounted for $38 \%$ of the variance in the patients' perceptions and $39 \%$ of the family members' perceptions of the positive aspects of the decision-process.

\section{Conclusions}

In this study we examined the decision process of families living with lung cancer.

Specifically, we identified determinants of patients' and family members' negative and positive perceptions of the family decision process using MLM, an appropriate dyadic analysis approach. We found that although patients' and family members' perceptions of the decision process were similar, on average, there was also significant variability in how patients and family members perceived the negative and positive aspects of the decision process. Significant determinants of negative perceptions of the decision process, for both patients and family members, included patients' and family members' own depressive symptoms and feelings of not being listened to by others. Significant determinants of the positive perceptions of the decision process included patients' and family members' own feelings of not being listened to by family members and being in a non-spousal family care dyad relationship (e.g. parent-adult child relationship). Additionally, for family members, positive perceptions were higher when the patients were older.

The most striking finding in this study was the significance of not feeling listened to as a determinant of the dyad's perceptions of the decision process. For patients and family members alike, it was a consistent finding across both models that the individuals' own rating of the difficulty they had in getting family to listen to their opinion influenced both the negative and positive perceptions of the decision process. When patients and family members primarily involved in caring for the patient had more difficulty getting their family to listen to their opinions, they had more negative perceptions of the decision process and fewer positive perceptions. These findings suggest the simple, yet crucial role of being heard in stressful situations such as a life-threatening illness. It is also possible to interpret this measure as proxy for another concept such as a feeling of solidarity or cohesion in a family relationship, which has been previously found to be related to more positive cancer-related decision making and communication (Siminoff et al., 2008; Zhang, 2003). Yet, we controlled for the patient's perception of the quality of his/her relationship with the family member, which is a similar concept and was not a significant determinant in our results.

Depressive symptoms were another determinant of the patients' and family members' negative perceptions of the decision process. The association between depressive symptoms and the negative perceptions of the decision process (e.g. perceptions of conflict, disagreement, becoming overly tense, avoidance) is consistent with previous studies on cancer-related decision making and communication (Siminoff et al., 2008; Zhang et al., 2010). Depressive symptoms were not significantly associated with perceptions of the positive aspects of the decision process in this study, which may indicate that the positive aspects (e.g. showing affection and respect) are more enduring and less susceptible to negative appraisals that can be exacerbated by depressive symptoms. Investigating this 
phenomenon with a qualitative approach would like yield more in-depth understanding. Unlike previous studies, we conceptualized depressive symptoms as a contextual factor influencing individuals' perceptions of the decision process, rather than the opposite direction. However, the lack of longitudinal data, both in this and in previous studies, makes it impossible to establish the direction of influence between depressive symptoms and the decision process of families living with lung cancer. Most likely, there is a recursive relationship between contextual factors and perceptions (Berg \& Upchurch, 2007); depressive symptoms could color the family care dyad's perceptions of the decision process and become colored by negative perceptions of the decision process, which is often ongoing in lung cancer.

Age and the type of kin relationship in the dyad also influenced the family members' positive perceptions of the decision process. The older the patients, the more positively the family members perceived the decision process. We controlled for actor effects and age was not a significant determinant of the patients' perceptions. Age is an important developmental aspect that contributes to dyadic perception and coping with an illness like lung cancer (Berg \& Upchurch, 2007). Consistent with previous research, when patients are older the impact of the illness is not as great as when it occurs at a younger age or earlier developmental stage, when illness is considered non-normative in families such as those that are raising young children or pursuing mid-career goals (Carter, Lyons, Stewart, Archbold, \& Scobee, 2010; Harden, 2005). In addition to older age, when dyads were comprised of spouses, rather than an adult child, family members had significantly more positive perceptions of the decision process. Our finding is similar to another study of lung cancer dyads where spouses had significantly more agreement over treatment decisions than dyads with adult children (Shin et al., 2013).

This study was limited by the homogeneity of the sample and the cross-sectional nature of the data, which made it difficult to generalize to other (non-White, younger) populations or determine whether our conceptualization of independent variables as predictors of dyads' perceptions of the family decision process was supported. Longitudinal research on the family decision process in lung cancer is needed to determine if the relationships between outcomes and predictors are supported, or are, in fact, reversed. This distinction will be important to intervention research aimed at the more modifiable factors that influence dyads' perceptions of the family decision process. In our study, modifiable factors included depressive symptoms and feelings of not being listened to by others. Additionally, while it was the goal of the current student to examine dyadic perceptions of the family's decision process, it was not possible to determine which particular family relationships (e.g. spouses, adult children and parents) were the source of the negative and positive perceptions. A more specific investigation of the influence of family relationship types in the decision process is necessary to gain this insight. Nevertheless, this study addresses a needed area of research and contributes new knowledge by providing a dyadic perspective of the positive and negative aspects of the family decision process in a life-threatening context. 


\section{Implications for Nursing}

Nurses assisting families with lung cancer decisions should be aware of the importance of the dynamics of the care dyad in how the decision process is perceived by both patients and their family members. In the context of lung cancer, it is important for both patients and family members to be heard in order to minimize negative perceptions and maximize positive perceptions of the decision process. Dyads exhibiting depressive symptoms are at significantly higher risk of negative perceptions of the decision process. Finally, nurses should be aware that dyads comprised of an adult child caring for a parent with lung cancer may not benefit from as much of the positive aspects of the decision process, such as affection and respect, as spouse dyads.

\section{Acknowledgments}

Funding Acknowledgements: This work was supported by the American Cancer Society (RSGPB-07-171-01CPPB) [K.S.L.], and the National Institute of Nursing Research of the National Institutes of Health (F31NR015195) [L.M.M] and the National Center for Research Resources of the National Institutes of Health through the OHSU Oregon Clinical and Translational Research Institute (5KL2TR000152-08) [D.R.S.]. The content is solely the responsibility of the authors and does not necessarily represent the official views of the funding agencies.

\section{References}

Archbold PG, Stewart BJ, Greenlick MR, Harvath T. Mutuality and preparedness as predictors of caregiver role strain. Res Nurs Health. 1990; 13:375-384. [PubMed: 2270302]

Badr H, Carmack Taylor CL. Social constraints and spousal communication in lung cancer. PsychoOncology. 2006; 15(8):673-683. [PubMed: 16287210]

Barnett RC, Marshall NL, Raudenbush SW, Brennan RT. Gender and the relationship between job experiences and psychological distress: A study of dual-earner couples. Journal of Personality and Social Psychology. 1993; 64(5):794-806. [PubMed: 8505708]

Berg CA, Upchurch R. A developmental-contextual model of couples coping with chronic illness across the adult life span. Psychol Bull. 2007; 133(6):920-954. DOI: 10.1037/0033-2909.133.6.920 [PubMed: 17967089]

Carter JH, Lyons KS, Stewart BJ, Archbold PG, Scobee R. Does age make a difference in caregiver strain? Comparison of young versus older caregivers in early-stage Parkinson's disease. Mov Disord. 2010; 25(6):724-730. DOI: 10.1002/mds.22888 [PubMed: 20201024]

Davison BJ, Goldenberg L, Gleave ME, Degner LF. Provision of individualized information to men and their partners to facilitate treatment decision making in prostate cancer. Oncol Nurs Forum. 2003; 30(1):107-114. [PubMed: 12515988]

Hagedoorn M, Kuijer RG, Wobbes T, Sanderman R. Marital satisfaction in patients with cancer: Does support from intimate partners benefit those who need it most? Health Psychology. 2000; 19(3): 274-282. [PubMed: 10868772]

Hagedoorn M, Sanderman R, Bolks HN, Tuinstra J, Coyne JC. Distress in couples coping with cancer: a meta-analysis and critical review of role and gender effects. Psychol Bull. 2008; 134(1):1-30. DOI: 10.1037/0033-2909.134.1.1 [PubMed: 18193993]

Harden J. Developmental life stage and couples' experiences with prostate cancer. Cancer Nursing. 2005; 28(2):85-98. [PubMed: 15815178]

Howlader, N., Noone, AM., Krapcho, M., Garshell, J., Miller, D., Altekruse, SF., ... Cronin, KA. SEER Cancer Statistic Review, 1975-2011. Bethesda, MD: 2013. Retrieved from: http:// seer.cancer.gov/csr/1975_2011/

Kramer BJ, Kavanaugh M, Trentham-Dietz A, Walsh M, Yonker JA. Predictors of family conflict at the end of life: the experience of spouses and adult children of persons with lung cancer. Gerontologist. 2010; 50(2):215-225. DOI: 10.1093/geront/gnp121 [PubMed: 19671660] 
Lobchuk MM, Murdoch R, McClement SE, McPherson CJ. A dyadic affair: Who is to blame for causing and controlling the patient's lung cancer? Cancer Nursing. 2008; 31(6):435-443. [PubMed: 18987510]

Lyons KS, Lee CS, Bennett JA, Nail LM, Fromme E, Hiatt SO, Sayer AG. Symptom incongruence trajectories in lung cancer dyads. Journal of Pain \& Symptom Management. 2014; 48(6):10311040. [PubMed: 24747222]

Lyons KS, Vellone E, Lee CS, Cocchieri A, Bidwell JT, D’Agostino F, ... Riegel B. A dyadic approach to managing heart failure with confidence. Journal of Cardiovascular Nursing. 2015; 30(4 Suppl 1):S64-71. [PubMed: 25658186]

Manne S, Ostroff J, Rini C, Fox K, Goldstein L, Grana G. The interpersonal process model of intimacy: the role of self-disclosure, partner disclosure, and partner responsiveness in interactions between breast cancer patients and their partners. J Fam Psychol. 2004; 18(4):589-599. DOI: 10.1037/0893-3200.18.4.589 [PubMed: 15598164]

Menne HL, Tucke SS, Whitlatch CJ, Feinberg LF. Decision-making involvement scale for individuals with dementia and family caregivers. American Journal of Alzheimer's Disease \& Other Dementias. 2008; 23(1):23-29.

Noelker, LS., Townsend, A., Deimling, GT. Caring for elders and the mental health of family members: A report on the study's first three years (1980-1983). The Benjamin Rose Institute; Cleveland, OH: 1984.

Radloff LS. The CES-D scale: A self-report depression scale for research in the general population. Applied Psychological Measurement. 1977; 1:385-401.

Raudenbush, SW., Bryk, AS., Congdon, R. HLM for Windows (Version 7). Skokie, IL: Scientific Software International, Inc; 2011.

Rose JH, Radziewicz R, Bowman KF, O'Toole EE. A coping and communication support intervention tailored to older patients diagnosed with late-stage cancer. Clinical Interventions in Aging. 2008; 3(1):77-95. [PubMed: 18488881]

Sayer, AG., Klute, MM. Analyzing couples and families: Multilevel methods. In: Bengtson, VL.Acock, AC.Allen, KR.Dilworth-Anderson, P., Klein, DM., editors. Sourcebook of Family Theory and Research. Thousand Oaks, CA: Sage Publications; 2005. p. 289-313.

Shin DW, Cho J, Roter DL, Kim SY, Sohn SK, Yoon MS, ... Park JH. Preferences for and experiences of family involvement in cancer treatment decision-making: patient-caregiver dyads study. Psychooncology. 2013; 22(11):2624-2631. DOI: 10.1002/pon.3339 [PubMed: 23893390]

Shin DW, Park JH, Shim EJ, Park JH, Choi JY, Kim SG, Park EC. The development of a comprehensive needs assessment tool for cancer-caregivers in patient-caregiver dyads. Psychooncology. 2011; 20(12):1342-1352. DOI: 10.1002/pon.1857 [PubMed: 22102594]

Siminoff LA, Dorflinger L, Agyemang A, Baker S, Wilson-Genderson M. Oncologists' assessments of lung cancer patient and family disagreements regarding treatment decision making. Lung Cancer. 2012; 77(1):212-216. DOI: 10.1016/j.lungcan.2012.02.008 [PubMed: 22405569]

Siminoff LA, Rose JH, Zhang AY, Zyzanski SJ. Measuring discord in treatment decision-making; Progress toward the developemnt of a cancer communication and decision-making assessment tool. Psycho-Oncology. 2006; 15:528-540. DOI: 10.1002/989 [PubMed: 16206332]

Siminoff LA, Wilson-Genderson M, Baker S Jr. Depressive symptoms in lung cancer patients and their family caregivers and the influence of family environment. Psychooncology. 2010; 19(12):12851293. DOI: 10.1002/pon.1696 [PubMed: 20119935]

Siminoff LA, Zyzanski SJ, Rose JH, Zhang AY. The Cancer Communication Assessment Tool for Patients and Families (CCAT-PF): a new measure. Psychooncology. 2008; 17(12):1216-1224. DOI: 10.1002/pon.1350 [PubMed: 18504807]

Stone AM, Mikucki-Enyart S, Middleton A, Caughlin JP, Brown LE. Caring for a parent with lung cancer: caregivers' perspectives on the role of communication. Qual Health Res. 2012; 22(7):957970. DOI: 10.1177/1049732312443428 [PubMed: 22645222]

Sullivan DR, Ganzini L, Duckart JP, Lopez-Chavez A, Deffebach ME, Thielke SM, Slatore CG. Treatment receipt and outcomes among lung cancer patients with depression. Clin Oncol (R Coll Radiol). 2014; 26(1):25-31. DOI: 10.1016/j.clon.2013.09.001 [PubMed: 24080122] 
Venetis MK, Greene K, Checton MG, Magsamen-Conrad K. Decision making in cancer-related topic avoidance. J Health Commun. 2015; 20(3):306-313. DOI: 10.1080/10810730.2014.965364 [PubMed: 25584820]

Ware, JE. How to Score the Version 2 of the SF-36 Health Survey. Boston, MA: The Health Institute of the New England Medical Center; 2005.

Zhang AY. The role of the family in treatment decision making by patients with cancer. Oncol Nurs Forum. 2003; 30(6):1022-1028. DOI: 10.1188/03.ONF.1022-1028\#sthash.BadnKEBJ.dpuf [PubMed: 14603359]

Zhang AY, Siminoff LA. Silence and cancer: Why do families and patients fail to communicate? Health Commun. 2003; 15(4):415-429. DOI: 10.1207/S15327027HC1504_03 [PubMed: 14527866]

Zhang AY, Zyzanski SJ, Siminoff LA. Differential patient-caregiver opinions of treatment and care for advanced lung cancer patients. Social Science \& Medicine. 2010; 70(8):1155-1158. DOI: 10.1016/j.socscimed.20 [PubMed: 20137849] 


\section{Table 1}

Sample demographics and descriptives ( $\mathrm{N}=109$ dyads)

\begin{tabular}{lcc}
\hline & Patient Mean (SD) or \% & Family Member Mean (SD) or \% \\
\hline Age in years & $68.68(11.75)$ & $60.90(13.60)$ \\
Female & $46 \%$ & $74 \%$ \\
Race/Ethnicity & & \\
$\quad$ White (Non-Hispanic) & $92.59 \%$ & $89.81 \%$ \\
Black/African-American & $1.85 \%$ & $.93 \%$ \\
Native American/Pacific Islander & $.93 \%$ & $1.85 \%$ \\
Asian & $.93 \%$ & $3.70 \%$ \\
Hispanic/Latino & $1.85 \%$ & $2.78 \%$ \\
Relationship to Patient & & \\
Spouse & - & $70.37 \%$ \\
Adult child & - & $23.15 \%$ \\
Neighbor or friend & - & $2.87 \%$ \\
Other family member & - & $3.70 \%$ \\
Stage IV lung cancer - Distant Metastasis & $33 \%$ & - \\
Physical health (SF-36, PCS scale 0-100) & - & $49.52(10.46)$ \\
Depressive symptoms (CES-D scale 0-60) & $12.03(10.16)$ & $11.72(8.48)$ \\
Relationship quality (Mutuality scale 0-4) & $3.55(0.41)$ & - \\
Feelings of not being listened to (scale 0-2) & $0.39(0.53)$ & $0.34(0.47)$ \\
\hline
\end{tabular}




\section{를}

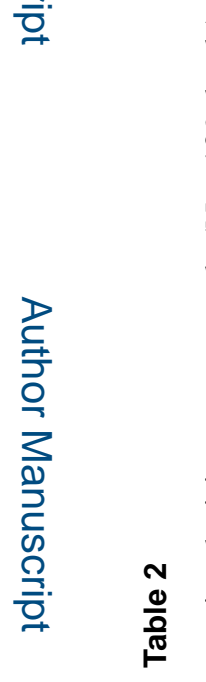

$\frac{\pi}{2}$

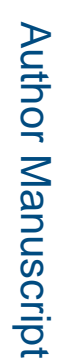

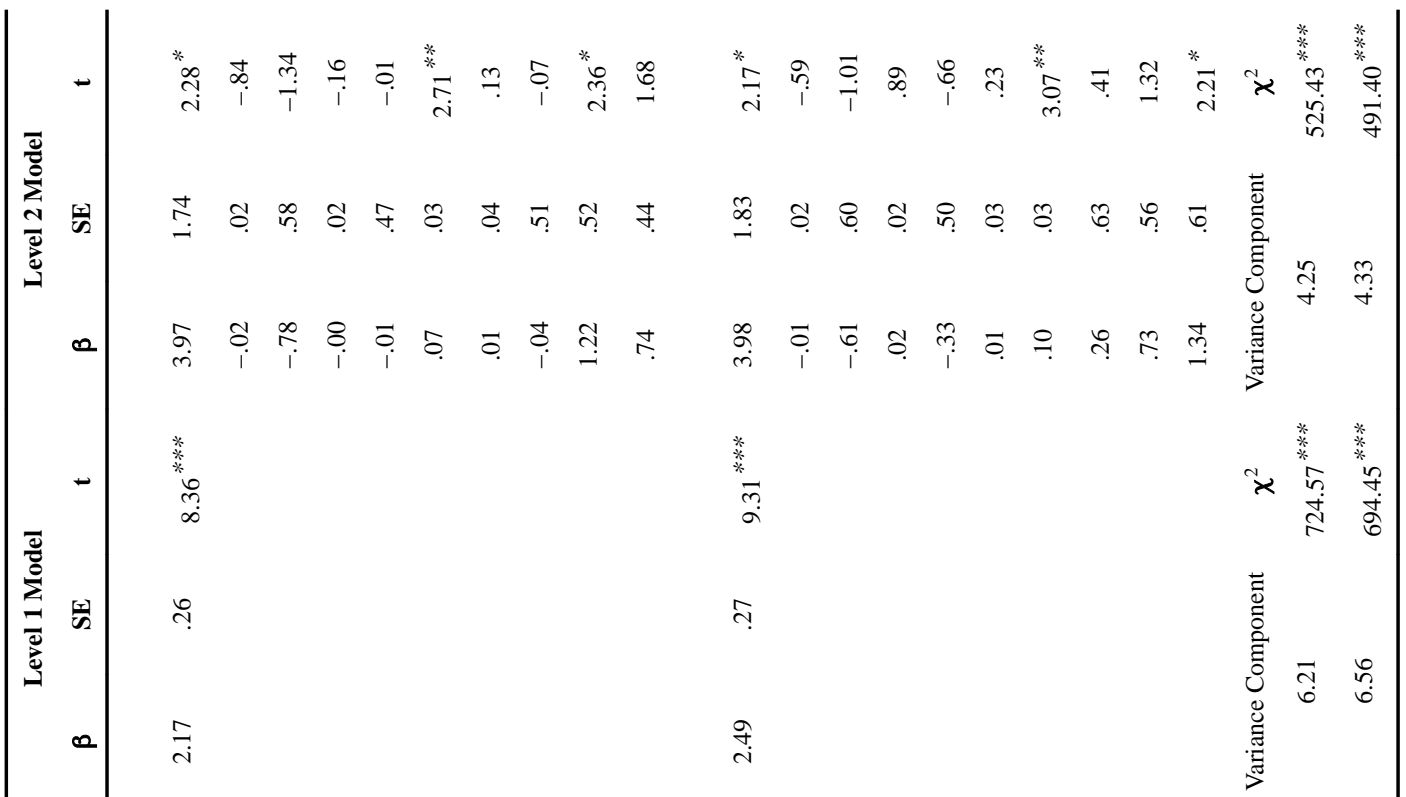

를

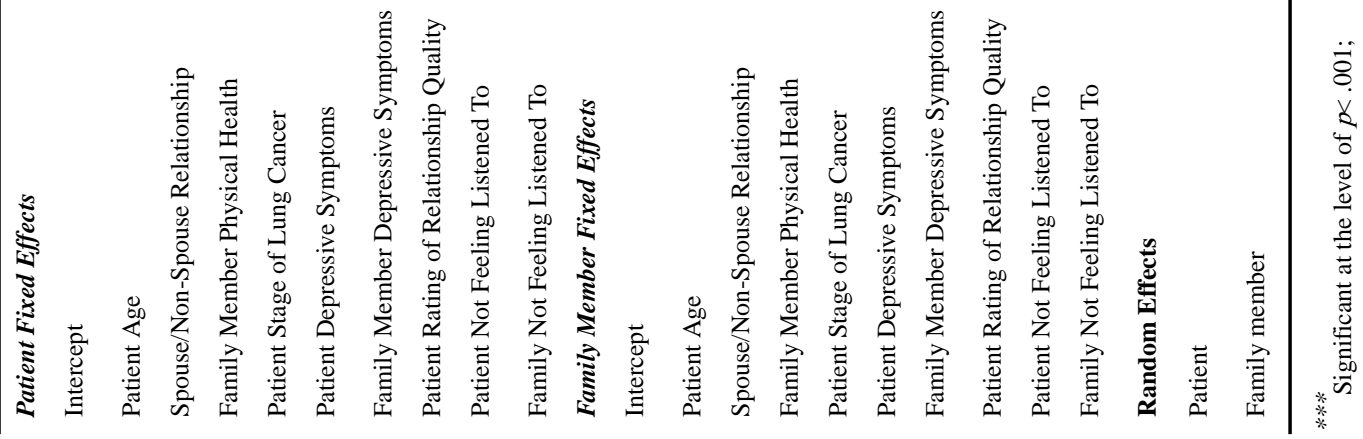

Oncol Nurs Forum. Author manuscript; available in PMC 2018 January 01. 

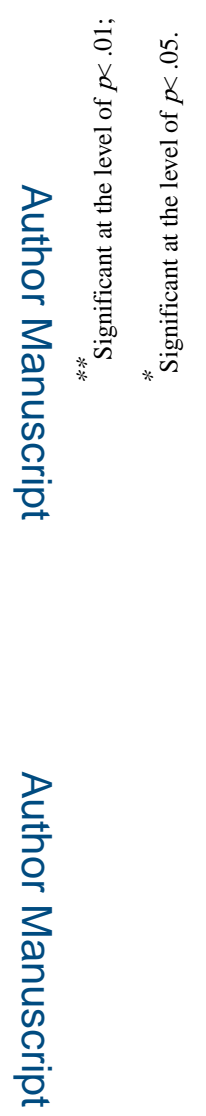

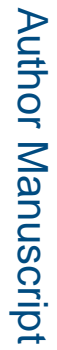

롤

Oncol Nurs Forum. Author manuscript; available in PMC 2018 January 01. 


\section{를}

$\frac{8}{8}$

8

$\begin{array}{r}3 \\ \geq \quad \frac{0}{\pi} \\ \hline\end{array}$

을

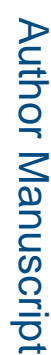

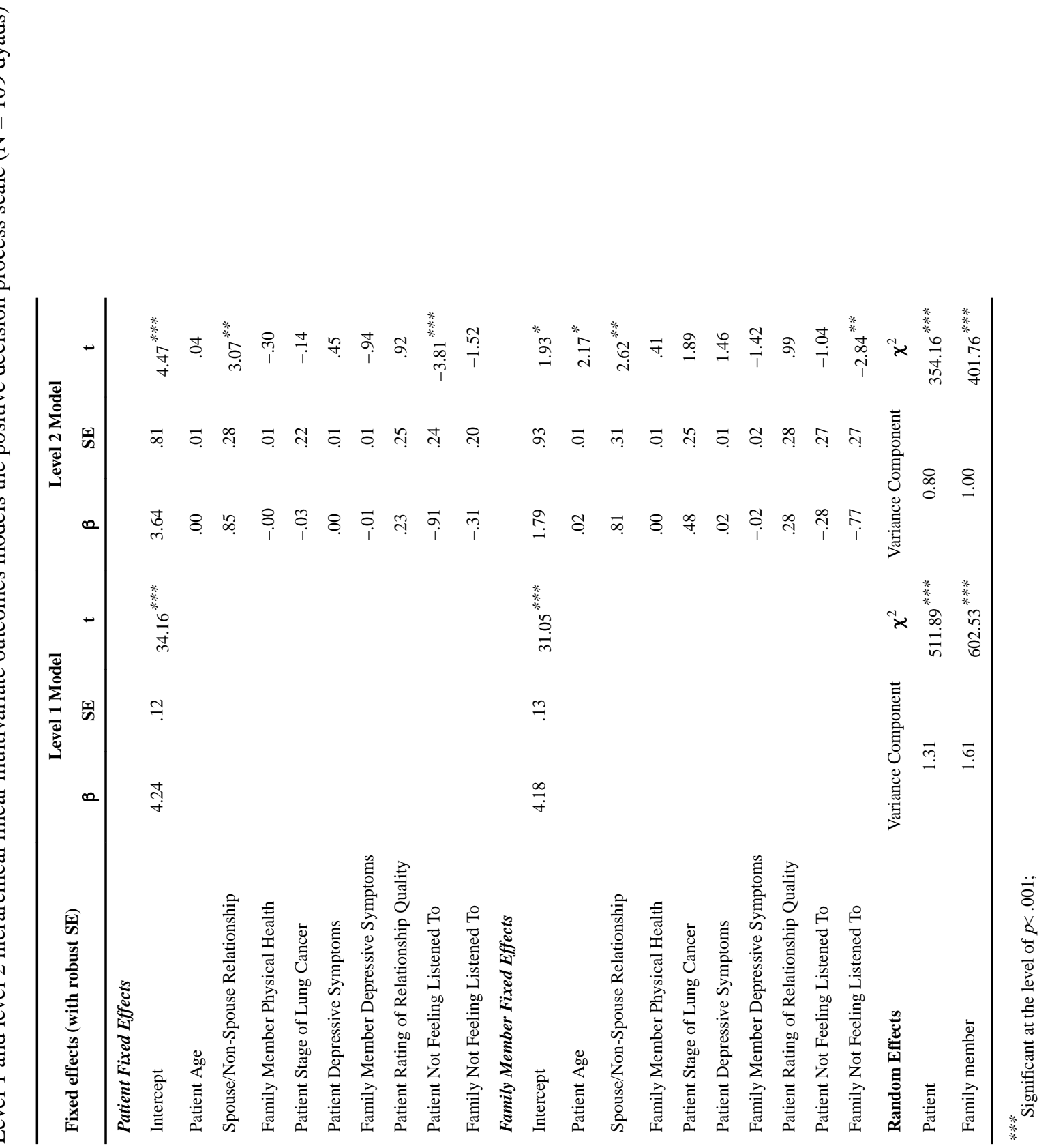

Oncol Nurs Forum. Author manuscript; available in PMC 2018 January 01. 

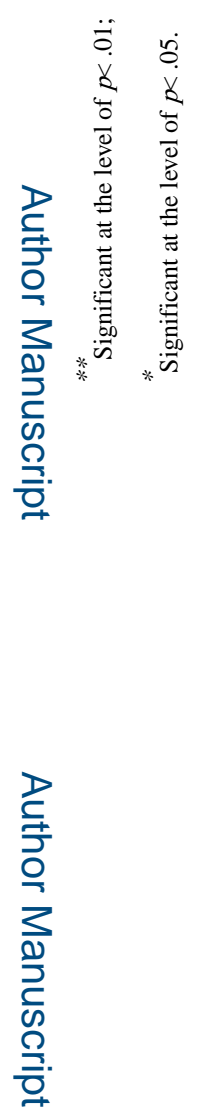

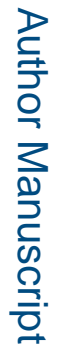

롤

Oncol Nurs Forum. Author manuscript; available in PMC 2018 January 01. 